\title{
PENGARUH MODERNISASI TERHADAP TRADISI PENDIDIKAN ANAK DALAM MASYARAKAT SUKU GAYO
}

\author{
Sukiman \\ Fakultas Ushuluddin UIN Sumatera Utara \\ Email:miqot@ymail.com
}

\section{Abstract}

The tradition of children education at Gayo typically begins since infant to childhood. At earlier stage, they learn by listening to chant, folktale, and learning from local Islamic scholars. However, in the modernization era, the tradition is worn off. Modernization has changed the youth at Gayo into spiritual depletion, lack in dynamic and creativity, moral degradation and inadequate friendship. To overcome the education crisis of the children in Gayo, it needs reorientation by integrated approach between the Islamic Shariah and the education tradition of Gayo. It is applied though functioning and coordinating between the official Islamic Shariah, the tradition institution of Gayo, and the deliberative board of ulama. Accordingly, the youth at Gayo will become more religious, godly and hold Islamic culture.

Tradisi pendidikan anak di Gayo memiliki sifat yang khas mulai dari lahir hingga mendidik anak masa balita. Masa awal pendidikan anak terdapat tradisi lantunan syair-syair, kisah legenda dan penyerahan anak kepada ulama kampung untuk belajar agama Islam. Namun dengan adanya modernisasi, tradisi ini mulai pudar. Modernisasi telah merubah generasi muda di Gayo menipis spiritualnya, kurang dinamis dan kurang kreatif, degradasi moralnya dan silaturrahimnya berkurang. Untuk mengatasi krisis pendidikan anak-anak Gayo ini perlu reorientasi dengan pendekatan integrasi antara syariat Islam dengan tradisi adat pendidikan Gayo. Aplikasinya adalah dengan memfungsikan dan bekerja sama antara Dinas Syariat Islam, Lembaga Adat Gayo dan Majelis Permusyawaratan Ulama. Dengan cara itulah, generasi muda Gayo ini akan menjadi orang-orang yang saleh, taqwa, berbudaya Islami.

Keywords: modernization, education tradition 


\section{Pendahuluan}

Suku Gayo mendiami beberapa daerah di Provinsi Aceh. Suku Gayo Lut mendiami Kabupaten Aceh Tengah dan Bener Meriah, sedangkan Gayo Alas atau Gayo Deret mendiami Kabupaten Gayo Lues dan Kabupaten Aceh Tenggara. Di daerah Aceh Timur juga terdapat Suku Gayo Lukup. Tulisan ini lebih fokus melihat tradisi pendidikan anak dalam masyarakat Gayo Lut yang berdomisili di Dataran Tinggi Gayo Kabupaten Aceh Tengah dan Bener Meriah. Masyarakat Suku Gayo memiliki tradisi khas seperti juga dengan tradisi suku-suku lain di Indonesia. Suku Gayo memiliki tradisi atau budaya melalui dua sumber; pertama, dari sumber leluhur yang bermuatan pengetahuan, keyakinan, nilai, norma-norma yang dinyatakan sebagai edet (adat) dan kebiasaan yang tidak mengikat yang disebut dengan resam (peraturan). Kedua, sumber agama Islam berupa akidah sistem keyakinan, nilai-nilai dan kaidah-kaidah agama yang disebut hukum (Melalatoa, 1997: 202).

Suku Gayo memiliki budaya dan adat istiadat yang sangat lengkap, salah satunya adalah tradisi mendidik anak, meskipun adat pendidikan ini merupakan bagian yang tidak terpisahkan dengan ajaran Islam. Tetapi lebih pada sistem atau metode yang mereka terapkan dalam mendidik anak-anak mereka agar menjadi orang-orang yang shaleh, bermartabat, dan selamat di dunia dan akhirat. Tradisi pendidikan ini sesungguhnya telah diawali dari tradisi perkawinan, memelihara anak dalam kandungan, tradisi aqiqah yang disertai dengan penabalan nama yang disebut dengan turun mani (turun mandi) dan mengasuh anak dari masa balita sampai dewasa (Melalatoa, 1982: 35).

Tradisi pendidikan anak dalam masyarakat Suku Gayo ini lebih pada cara yang turun temurun dilakukan oleh orang tua terdahulu kepada keturunan mereka berikutnya. Sedangkan materi pendidikannya tetap mengacu kepada nilai-nilai ajaran Islam berupa akidah, ibadah, muamalah, akhlak dan aturan hidup yang Islami. Akan tetapi, dewasa ini kemajuan informasi ilmu dan teknologi yang semakin pesat maka tradisi pendidikan anak di Gayo sudah pudar dan cenderung hilang akibat arus modernisasi ini memasuki daerah Gayo. Disadari juga bahwa modernisasi ini membawa manfaat terutama memperluas wawasan anak-anak Gayo, akan tetapi dampak negatif yang ditimbulkannya jauh lebih buruk sehingga dapat menjauhkan mereka dengan ajaran Islam. Sekiranya anak orang Gayo jauh dari Islam, maka akan menjadi orang yang kufur kepada Allah yang kelak akan menerima kesengsaraan di akhirat. Tidak terlalu naif jika tradisi pendidikan anak di Gayo ini diterapkan lagi agar terwujud generasi muda Gayo yang Islami, beradat dan berbudaya. 


\section{Sekilas tentang Tradisi Pendidikan Anak di Gayo}

Secara kasat mata tradisi pendidikan anak di Gayo diawali saat ia lahir, tentu saja mengikuti syariat Islam dengan cara mengazan dan mengiqamatkan di telinga anak yang baru saja lahir. Tetapi dalam pemberian dan penabalan nama terdapat tradisi pendidikan, yaitu pada hari ketujuh ada acara turun mani (turun mandi) yaitu anak ini dibawa ke tempat permandian untuk dimandikan. Apabila bayi itu perempuan maka pihak ralik (nenek dari ibu si bayi) yang memakai pakaian bagus harus menyuntingkan jeruk purut (mungkur) pada sanggulnya. Sebaliknya jika bayi laki-laki maka ralik tadi harus melilitkan di kepalanya sejenis tumbuh-tumbuhan menjalar yang dinamakan bulang keriris. Sewaktu pergi ke tempat permandian, biasanya membawa ampang (tempat duduk orang terhormat), buah kelapa, parang dan sepotong kain tua yang dibakar (demi) dan kacip (kelati) sebagai bahan untuk menangkal gangguan setan. Di tempat upacara inilah kelapa dibelah dengan parang persis di atas kepala bayi itu agar tidak takut pada petir (pungi) setelah itu bayi dimandikan (Melalatoa, 1982: 91). Tradisi ini memberi pelajaran agar hidup dijalani dengan berani, berusaha dan berjuang. Air kelapa sendiri sebagai simbul kesucian dan dapat diminum ketika dahaga. Hal ini menandakan hidup ini harus bersih, baik dan dimanfaatkan hanya untuk kebaikan dan kebenaran. Setelah itu, bayi ini diserahkan kepada imem kampong (ulama) untuk dikendurikan dan ditabelkan namanya, dan nama yang diberikan itupun sudah dipilih dari usulan para kerabat, tamu yang hadir dalam acara itu melalui selembar kertas, sang ayah dan ibunya memilih salah satu nama yang mereka setujui dan nama itulah yang akan ditabalkan oleh Tengku Imam kepada sang bayi. Pada acara kenduri juga dibacakan ayat suci al Quran, shalawat Nabi dan doa-doa agar anak ini kelak menjadi anak yang shaleh. Hal itu juga sebagai isyarat bahwa anak bayi ini telah diajarkan hidup secara bermasyarakat yang harmonis dan relegius.

Tahapan berikutnya, bayi diasuh oleh orang tua terutama ibu (ine) yang selalu mendidik rasa keagamaan anak dengan cara mendendangkan lagu yang bernilai tauhid ketika anaknya masih dalam ayaunan atau menjelang tidur dengan syair "La ilaha illallah Muhamadun Rasulullah, anakuni jema mutuah, umure gelah lanyut rejekie gelah mudah" artinya tidak ada Tuhan kecuali Allah dan Muhammad utusan Allah. Diharapkan sang anak mendapat harkat atau anugerah dari Allah, umurnya panjang dan rejekinya dimudahkan Allah (Syukri, 2006: 193). Kalimat ini terus didendangkan setiap waktu sehingga memberi peluang terhadap makbulnya doa ibu untuk mendoakan anaknya meraih martabat yang mulia dan terhormat. Setelah anak berusia dua tahun, 
terdapat tradisi upacara sapihan menyusui (jawe). Selama tiga hari tubuh bayi ini selalu diguyur dengan gelasah yaitu air yang berasal dari ramuan makan sirih dengan perangkat pinang, konyel (dari kulit kayu). Selama tiga hari, sang anak makan telor, pisang, bertih (padi yang digongseng), bahkan disediakan makanan khas gutel yaitu pulut yang ditumbuk dan dibulati serta dilumuri gula dan kelapa lalu direbus. Tradisi ini mengisyaratkan akan memulai kehidupan yang mandiri dan berkreasi, hal itulah yang terus menerus dilakukan dengan cara membimbing anaknya untuk mandiri. Maka sudah keniscayaan bahwa anak Gayo ketika masa sekolah sudah dapat membuat layangan, mobil-mobilan, pistol-pistolan dan permainan anak-anak lainnya (Melalatoa, 1982: 92).

Selanjutnya ayah dan ibu (ine urum ama) maupun neneknya menyampaikan ajaran agama dan falsafah atau pedoman hidup lewat pengisahan legendalegenda (kekeberen). Lewat kekeberen (kisah) inilah, anak-anak Gayo belajar tentang hidup dan agama terutama bagaimana membina mental relegius sorang anak. Setelah berumur 7-8 tahun, orang tua mulai menyerahkan anaknya kepada Tengku imem dengan membawa sepiring bertih (padi yang digonseng) untuk dididik membaca dan mengetahui makna al Quran yang didahului dengan mempelajari huruf hijaiyah dan Juz Amma (Ibrahim, 1986: 13). Penyerahan anak kepada imem (guru) yang dianggap sederajat dengan orang tuaya sendiri karenanya menyerahkan anak kepada imem harus mengikuti aturan dan adab tententu. Menurut Ibrahim, terdapat adab menyerahkan anak kepada Tengku imem, wali murid harus mengikuti tata cara dan berbahasa yang beradab yaitu: "Bismillahirrahmanirrahim, assalamu'alaikum wr.wr. Tengku terbilangsi jeroh ketike sibise kami geh roa tujuen, selapis menentong tengku, selapismi kami menyerahen anak ni kami iejer urum ididik tengku kena ngeitakdirni Tuhen kami melahir urum munekulne." Artinya, Tengku kami datang dengan dua tujuan, pertama mengunjungi Tengku dan kedua menyerahkan anak ini kepada Tengku untuk diajar dan dididik, karena Allah SWT telah menakdirkan kami melahirkan dan membesarkannnya. Lalu, Tengku imem menyambut penyerahan itu dengan kata "Bismillahirrahmannirrahim, urum niet si ikhlas aku nge munerime anakteni untuk iejer buge-buge we mujadi anak amal saleh." Artinya: dengan niat yang ikhlas sya sudah menerima anak kita ini, mudah-mudahan menjadi anak amal shaleh) (Ibrahim, 1986:158). Tata cara penyerahan ini merupakan ketulusan pihak orang tua dan Tengku imem untuk mendidik anak ini yang kelak akan menjadi orang yang shaleh.

Apabila anak telah mampu mengenal dan menghafal huruf hijaiyah dan membaca Juz Amma, ini menjadi kebanggaan pertama bagi keluarga dan 
Tengku imem yang mengajarkannya. Khatam al Quran merupakan puncak kebanggaan karena orang tua merasa anaknya telah mendekatkan diri kepada Allah. Selanjutnya sang anak belajar berwudhu (bersuci), shalat lima waktu dan ibadah-ibadah lainnya. Pada usia ini anak-anak Gayo ini mulai mengikuti kegiatan pengajian di masjid, mersah dan joyah dengan para Tengku (Paeni, 2003: 186). Sebagai tempat mengaji, halaman masjid dijadikan tempat bermain sepak bola, bola kasti, main hong, main kemili (biji kemiri) dan mandi di kolam masjid. Bahkan setiap bulan Ramadhan anak-anak Gayo ini manjadikan masjid sebagi sentral aktivitas remaja, sehingga dapat dipastikan pengaruh spiritual dari masjid itu telah merasuk ke dalam jiwa anak Gayo. Pada usia sekolah, anak-anak Gayo mengikuti pendidikan formal di sekolah seperti pesanteren, Madrasah Ibtidaiyah yang lebih kental dengan ilmu-ilmu agama, dan ada pula mereka yang masuk ke sekolah umum seperti Sekolah Dasar, tetapi dengan dasar agama yang kuat yang telah mengikuti pendidikan Islam dalam masyarakat.

\section{Dampak Modernisasi terhadap Tradisi Pendidikan Anak di Gayo}

Sampai tahun 1980-an Dataran Tinggi Gayo belum tersentuh siaran televisi, hanya radio sebagai sarana informasi dan hiburan saat itu. Maka hampir dipastikan tradisi pendidikan anak masih dilakukan dan terintegrasi dengan pendidikan formal di sekolah. Tetapi kemajuan ilmu pengetahuan dan teknologi semakin pesat terutama dalam bidang informasi yang sangat canggih, sehingga apa saja peristiwa yang terjadi di belahan dunia ini dapat disaksikan oleh manusia di bagian bumi lainnya melalui siaran televisi, radio dan jaringan internet termasuk daerah Gayo. Kehadiran internet tidak hanya memberikan informasi aktivitas manusia di bumi ini, bahkan dapat menggerakkan perubahan politik di sebuah negara. Bukan hanya itu, alat komunikasi inipun mampu menularkan penyakit dari negara maju ke negara berkembang. Menurut WHO, penyakit jantung merupakan penyakit menular yang baru atau disebut dengan new communicable disease. Penyakit menular yang baru ini bukanlah disebabkan oleh bakteri atau kuman tertentu, tetapi penularannya yang semakin luas ke seluruh muka bumi ini yang berhubungan dengan semakin pesatnya media komunikasi. Media komunikasi bukanlah menularkan kuman atau virus, melainkan menyiarkan berbagai pola hidup yang salah, baik itu dari media cetak maupun elektronik. Pola hidup yang salah di negara maju, melalui berbagai media komunikasi akan menular dengan pesat ke negara-negara yang berkembang. Contoh, negara maju telah terbiasa 
dengan makanan cepat saji yang kadar gizinya tidak seimbang. Pola hidup ini akan segera ditiru oleh masyarakat di negara-negara berkembang termasuk di Indonesia (Bihar, 2012: 28).

Menurut puturolog Amerika John Naisbitt dan Patrica Aburdene, pada abad 21 gaya hidup di seluruh dunia menunjukkan kesamaan, yaitu 3 F: food, fashion, dan fun (makanan, mode, dan hiburan). Kemudian, Jalaluddin Rakhmat menambahkan dengan $5 \mathrm{~F}$ yaitu: faith, fear, facts, fiction dan formulation (Rakhmat, 1991: 71). (1). Food (makanan), yang ada di di negara luar telah ada pula terhidang dan dinikmati oleh orang Gayo seperti Fried Chicken, Mac Donald serta minuman dan buah-buahan dari Cina, Thailand telah mendarat di daerah ini. Makanan, minuman yang diproduksi ini perlu dirisaukan karena bahannya berasal dari barang yang masih diragukan halal secara zat atau pembuatannya. Jika dipastikan benda-benda itu telah bercampur antara halal dan haram, maka hal ini dapat menyebabkan dosa dan tidak makbulnya doa. Dalam ajaran Islam, perbuatan yang memakan makanan yang haram ini akan mengakibatkan darahnya dirasuki oleh gaya hidup setan yang selalu menimbulkan maksiat; (2). Fashion (mode pakaian), yang telah dirancang oleh perancang dunia di Eropa dan dipasarkan melalui majalah mode ke seluruh dunia. Mode dan rancangan pakaian wanita terutama sangat seksi dan dapat menuai gairah kaum laki-laki, akibatnya pakaian waita ini sangat mengganggu pandangan umat Islam. Padahal Islam mengajarkan kaum wanita wajib menutup aurat (Sou'yb, 1987: 70); (3). Fun (hiburan), masa kini telah menjadi bisnis internasional sehingga para artis dan aktor telah menjadi komoditas dunia sehingga kegiatan hiburan inipun telah dapat diakses dalam waktu sekejap. Kegiatan hiburan dari berbagai belahan dunia ini telah begitu merasuk ke dalam jiwa rakyat Indonesia termasuk di daerah Gayo.

Sekularisasi dan liberalisme merupakan akibat yang tidak terelakkan dari proses modernisasi bangsa. Sekularisasi tanpa modernisasi tak ubahnya bagaikan mata uang yang tidak mungkin dipisahkan satu sama lain. Oleh karena itu, dalam diskursus ilmu sosial atau sosiologi ada sebuah teori terkenal yang mengatakan bahwa, makin maju suatu masyarakat, maka makin menurun komitmen mereka pada agama. "Maju" disini maksudnya adalah "modern" (Madjid, 1992: 451-452). Modernisasi dipercaya bakal menghalau agama dari ruang dan institusi publik. Hal ini sangat berbahaya bagi penganutnya. Bahkan dampak modernisasi menurunkan arti dan vitalitas agama bagi kehidupan masyarakat serta menggantikannya dengan "tuhan-tuhan" baru. Dalam proses menuju kemodernan ini, sekularisasi menjadi sebuah keniscayaan. Modernisasi 
tanpa sekularisasi keduanya sangat intens dalam menghalau agama dari ajaran yang sakral dan fundamental.

Di dunia Islam, sekularisasi bukan hanya sebuah proses, tetapi juga telah menjadi paradigma, ideologi, dan dogma yang diyakini kebenarannya dan dianggap secara sistematis dan terencana. Bahkan sekularisasi dianggap sebagai prasyarat transformasi dari cara tradisional/ kuno/ klasik menuju cara modern. Namun untuk mengurangi resistensi digunakanlah istilah lain yang lebih halus seperti modernisasi, pembangunan (development), demokratisasi, dan liberaliasi. Di dunia Islam berada dalam zaman keemasannya dari abad VII sampai abad XIII M (Hanafi, 1983: 79-80). Namun di saat Eropa memasuki zaman Renaissance yang membawa kepada zaman modern justru umat Islam mulai menurun, mundur, dan terjerembab kepada zaman kemunduran. Ilmu pengetahuan dan filsafat yang sudah lama bertahta di dunia Islam, kini memperoleh lahan subur untuk berkembang pesat di bumi Eropa (Rasyidi, 1985: 283). Sekularisasi yang sama juga terjadi di negara-negara Muslim lainnya. Proses sekular dan westernisasi ini disokong oleh sejumlah pemikir liberal pada masa itu, seperti Sir Sayyid Ahmad Khan, Nawwab Abd al-Latif, Mustafa Khan, dan Khuda Bakhsh. Demikian juga di Mesir, Qasim Amin (1863-1908) murid Syekh Muhammad Abduh yang menganggap syariat Islam sebagai kendala kemajuan sehingga tidak wajib berjiblab dan terjadi pelanggaran poligami. Ia menyampaikan bahwa hanya dengan nasionalisme dan modernisasi, negara Mesir dan negara-negara muslim lainnya dapat maju seperti negara Eropa (Raziq, 1925: 53-91).

Di Indonesia, sekularisasi telah berjalan sejak zaman kolonial Belanda yang melarang keras ekspresi keagamaan, khususnya Islam. Islam bagi banyak rakyat Nusantara bukan semata-mata agama, melainkan ideologi gerakan, bahkan napas kehidupan. Zaman kolonial Belanda mendukung pengembangan Islam di bidang ritual keagamaan, tetapi mencegahnya untuk berperan dalam bidang politik. Selain itu, untuk mengimbangi peran pesantren dan melanggengkan kekuasaan kolonial, maka dibuatlah lembaga-lembaga pendidikan atau sekolah-sekolah sekular untuk pribumi dengan tujuan mencetak warga yang bukan hanya siap mengisi birokrasi, tetapi juga kooperatif dan loyal terhadap kolonial. Bahaya sekularisasi ini bukan hanya dalam upaya menyingkirkan agama dalam kehidupan publik, melainkan juga sangat berbahaya di sektor pendidikan Islam. Idealnya tujuan pendidikan Islam tidak terlepas dari tujuan hidup manusia dalam Islam, yaitu untuk menciptakan pribadi-pribadi hamba Allah yang selalu bertaqwa kepada Allah SWT, dan dapat mencapai kehidupan yang 
bahagia dunia dan akhirat, sebagaimana terdapat dalam QS al Dzariat: 56 dan QS Ali Imran: 102. Dalam konteks sosial masyarakat, adanya sekularisasi di Gayo menyebabkan tujuan akhir dari pendidikan Islam sirna. Pendidikan Islam dengan seluruh totalitasnya dalam konteks Islam inheren dengan istilah "tarbiyah", "ta'lim" dan "ta'did" yang seharusnya dipahami, dihayati dan dilaksanakan secara bersama-sama dengan ajaran Islam dan tidak terpisahkan.

Semangat sekularisasi dan humanisme sampai saat ini sangat mendominasi terhadap dasar-dasar pendidikan dan pengajaran agama Islam, termasuk terhadap dasar-dasar ilmu dan pengetahuan. Asumsi-asumsi positivisme masih tetap digunakan dan dipaksa oleh manusia abad modern saat ini dalam segala segi kehidupan. Materialisme hampir menutupi pandangan spiritualisme dan berusaha untuk menggantinya dengan paradigma baru yang sekular dan cenderung meremehkan Tuhan. Paradigma ilmu sekuler yang berkembang sekarang lebih banyak berorientasi pada otak dan otot yang kering dari nilainilai spiritual. Sesungguhnya keadaan ini merupakan suatu ancaman nyata gerakan sekularisasi terhadap kelangsungan hidup masa depan umat manusia, agama, budaya, bangsa, dan negara khususnya bagi generasi muda di Dataran Tinggi Gayo.

Berikut pengaruh lain dari modernisasi ini secara lebih spesifik terhadap pendidikan anak di Gayo yaitu; pertama, menipis spiritualisme yang terlihat dari kurangnya melakukan ibadah baik shalat wajib, puasa ramadahan diakibatkan minimnya ilmu keislaman yang mereka miliki. Terkait dengan hal itu, kegiatan pengajian remaja Gayo kurang diminati karena mereka lebih asyik menonton TV menikmati hiburan daripada menambah ilmu keislaman secara informal di masjid maupun mushalla. Menipisnya spiritual remaja ini juga ditandai dengan semakin menjauhnya mereka dari aktivitas masjid yang dulunya dijadikan pusat kegiatan anak dan remaja di Gayo. Kedua, remaja lebih dependen dan serba instan karena mereka kurang berkereasi dalam menciptakan keterampilan. Mereka pergi ke pasar membeli apa saja yang mereka kehendaki, sehingga mereka tidak mampu mandiri dalam menjalani kehidupan. Keadaan itu membuat anak remaja di Gayo tidak kreatif, kurang dinamis sehingga mereka selalu dibantu oleh keluarga dan kelak tidak dapat berinteraksi dengan lingkungannya untuk mengembangkan dirinya. Padahal ciri orang Gayo adalah dinamis, keratif dan mengembara mencari ilmu ke luar daerah. Menurut Melalatoa (1992: 147), pendidikan tradisional di lingkungan keluarga adalah pengenalan terhadap lingkungan sosial dimulai dengan pengasuhan anak, kemudian anak akan mengenal dan menyesuaikan 
diri dengan lingkungannya. Ketiga, degradasi moral berupa kepribadian yang semu dimana mereka kurang mengindahkan tata krama adat istiadat, tidak menggunakan tutur tradisi Gayo kepada anggota keluarga (Pinan, 1998: 161). Tradisi tutur dalam adat Gayo adalah sebagai jati diri dan tata krama bergaul sehingga karekter, sikap seharusnya berbeda ketika bertemu dengan anggota keluarga sesuai dengan tingkatan orang yang bertutur kepadanya. Akibatnya akhlak remaja ini semakin rendah, hal ini tampak dalam pergaulan sehari-hari baik dalam keluarga, tetangga dan masyarakat. Pandangan seperti itu dari waktu kewaktu semakin menghawatirkan yang membuat anak-anak Gayo ini semakin terkikis moralitasnya dan akan terjerembab kepada perbuatan maksiat. Umat manusia yang banyak melakukan dosa, selalu saja mendapat peringatan dari Allah SWT sebagaimana firman Allah dalam Surat al Ankabut: 40:

"Masing-masing Kami siksa, karena dosa-dosanya diantara mereka ada yang Kami kirim kepadanya angin tofan (yang mengandung pasir) dan di antara mereka ada yang disiksa oleh teriakan keras dan diantara mereka ada yang Kami benamkan ke dalam bumi, dan diantara mereka ada yang kami tenggelakan ke dalam laut, Allah tiada menganiaya mereka, tetapi merekalah yang menganiaya diri mereka sendiri”.

Keempat, silaturrahim berkurang sehingga lebih mementingkan individu dan kepentingan sesaat. Masa kini tidak ada lagi gotong royong (bejamu), seperti menggirik padi, menyankol, atau kegiatan bersawah secara bersama-sama tanpa upah. Ketika hari raya tidak terlihat saling berkunjung dari rumah ke rumah secara menyeluruh, kecuali hanya keluarga terdekat. Akibat menipisnya silaturahim membuat pergaulan antar belah (sub suku) dapat terganggu dan memungkinkan akan terjadi pernikahan antar belah yang sesungguhnya dilarang secara adat. Jika hal itu terjadi maka akan ada efek negatif dalam masyarakat yang meruntuhkan harga diri mereka sendiri. Dahulu silaturahim ini sangat kuat sehingga persatuan dan kesatuan anak dan remaja di Gayo tertata rapi dan terjadi kekerabatan di bawah panji adat dan Syariat Islam.

\section{Alternatif Strategis Mengatasi Krisis Pendidikan Islam di Gayo}

Sejalan dengan julukan Aceh sebagai Serambi Makkah, di mana Gayo adalah bagian dari wilayah Aceh yang memiliki keistimewaan dalam bidang agama, adat dan pendidikan. Suku Gayo diharapkan tidak akan kehilangan jati diri sebagai umat Islam yang kaffah dan jauh dari perbuatan munkar. Terlebih Aceh telah menjadi satu-satunya provinsi di Indonesia yang menjadikan Syariat Islam sebagai dasar kehidupan bernegara dan berbangsa 
yang bertujuan menjadikan rakyat Aceh sejahtera dan relegius. Akan tetapi secara factual, dalam masyarakat Aceh di Gayo masih terdapat warga yang belum melaksanakan syariat Islam scara murni, utuh dan konsekuen. Hal ini terbukti masih banyaknya warga yang melakukan pelanggaran ajaran Islam melakukan maksiat seperti narkoba, pelecehan seksual dan kejahatan lainya yang saat ini telah dipublikasikan dalam surat-surat kabar. Menurut penulis, hal itu mesti dilakukan perubahan secara komprehensif dan simultan, terutama mengatasi pengaruh modernisasi yang telah disebutkan di atas, khususnya di Dataran Tinggi Gayo.

Untuk memperbaiki pendidikan Islam di kalangan generasi muda Gayo ini salah satu solusinya ialah dengan cara mengintegrasikan syariat Islam dengan adat istiadat Gayo yang sudah melekat dalam kehidupan masyarakat Gayo, karena antara syariat dan adat sudah menyatu seperti zat dan sifat. Secara kelembagaan juga telah dibentuk lembaga yang menangani kedua aspek tersebut, yaitu Dinas Syariat Islam yang mengurusi pelaksanaan ajaran Islam di tengah-tengah masyarakat, sedangkan terkait dengan aspek adat istiadat telah dibentuk lembaga Majelis Adat Aceh (MAA). Dinas Syariat Islam diharapkan berjalan secara fungsional untuk melakukan penyuluhan tentang Syariat Islam kepada seluruh lapisan masyarakat Gayo terutama generasi mudanya, sehingga mereka mengetahui dan mengamalkan syariat secara kaffah. Menurut Al Yasa Abubakar bahwa, umat Islam yang berdiam di Aceh khususnya maupun di Indonesia umumnya harus melaksanakan syariat Islam secara kaffah dalam hidup keseharian, baik kehidupan secara pribadi atau kehidupan bermasyarakat (Abubakar, 2006: 66). Sekiranya pengamalan Islam secara kaffah ini berjalan dengan baik di Gayo, sehingga generasi muda memiliki iman yang kukuh, ibadah yang kuat baik dan benar, muamalah (hubungan antar mansia dan alam) yang harmonis dan berakhlakul karimah. Profil tersebut seperti yang dicontohkan oleh Allah dalam QS Ibrahim: 24-25 yang artinya:

"Tidaklah kamu perhatikan bagaimana Allah telah membuat conto kalimat yang baik seperti pohon yang baik akarnya kuat dan cabangnya (menjulang) ke langit. (pohon itu) menghsilkan buahnya pada setiap waktu dengan seizin Tuhannya. Dan Allah membuat perumpamaan itu untuk manusia agar mereka selalu ingat"

Agar Syariat Islam ini berjalan dengan baik di Gayo, maka adat istiadat menjadi pagarnya, sehingga Lembaga Adat Gayo juga perlu difungsikan. Adapun lembaga adat di Gayo meliputi Sarakopat, Imem Mukim, Kepala Kampung, 
Imem Kampung, Biden, Juru Bie, Pawang Laut, Hariye, Pengulu Uten, Kejurun Belang, Rakyat Mupakat (Himpunan Qanun, 2002:145). Jika dilihat fungsi Sarakopat, yang terdiri dari (1). Reje (raja) bertugas untuk menegakkan dan memelihara keadilan dalam masyarakat. (2) Petue bertugas menyelidiki dan meneliti keadaan rakyat. (3) Imem (ulama) bertugas melaksanakan dan mengevaluasi syariat agama Islam, dan (4) Rakyat berdaulat yang berkewajiban mengadakan musyawarah dan mufakat (Syukri, 2006: 39). Sarakopat ini hampir mirip dengan pilar dunia yang disabdakan oleh Rasulullah dalam sebuah hadisnya yang bermakna: "Dunia ini seperti kebun yang memilki lima pilar yaitu, ilmunya ulama, adilnya pemerintah, kejujuran ahli ekonomi, pengabdian dari rakyat dan disiplinnya pegawai" (Razi, 1985: 168). Jika Sarakopat benar-benar difungsikan maka syariat Islam akan berjalan dengan baik, karena fungsi dari lembaga adat ini adalah untuk mencegah dan menindak perbuatan sumang (sumbang), melaksanakan adat istiadat, kebiasaan-kebiasaan dan sanksi adat, menyelesaikan kemalun edet empat perkara, madu opat (perbuatan yang dilarang) seperti penghinaan, menista, merampas harta atau mencuri, merampas hak orang lain (Syukri, 2006: 127). Apabila Majelis Adat Aceh di Gayo berjalan dengan baik, terutama mengembalikan tradisi pendidikan anak Gayo dan melakukan sosialisasi melalui penataran dan konsultasi adat Gayo bidang pendidikan, maka akan terbinalah karakter remaja yang shaleh, beradat dan budaya Islami.

Untuk memperkuat integrasi antara syariat Islam dengan adat istiadat Gayo ini, peran ulama (Majelis Permusyawaratan Ulama) sangat penting dan menjadi ujung tombak menyampaikan dan membimbing ajaran Islam kepada masyarakat. Ulama sesungguhnya berfungsi sebagai konseptor pelaksanaan syariat Islam, apakah konsep syariat yang dijalankan sesuai dengan pemahaman yang dilakukan para ulama termasuk peran ulama memberikan pengawasan pada pelaksanaannya. Islam adalah ajaran yang penuh kasih saying antar umat manusia, sehingga pelaksanaannya jangan sampai memberikan nilai-nilai yang menyeramkan dan menakutkan. Islam menawarkan ajaran yang damai, harmonis dan motivasi mayarakat untuk mencapai kemajuan (Syukri, 2012: 220). Jadi ulama berkewajiban mengarahkan, membina pendidikan Islam bagi anak-anak generasi muda Gayo untuk kesejahteraan di dunia dan akhirat.

\section{Simpulan}

Tradisi pendidikan anak di Gayo memiliki sifat yang khas mulai dari pernikahan, memelihara anak dalam kandungan, turun mani, mendidik anak 
masa balita. Masa ini awal pendidikan anak dengan melantunkan syair-syair, kekeberen dan penyerahan anak kepada imem kampung untuk belajar agama Islam. Setelah itu anak di dimasukkan secara formal ke pesantren dan madrasah. Pendidikan di masyarakat tetap dilakukan berbasis masjid, mushala dan joyah untuk mempelajari budaya dan ilmu Islam sebagai pedoman hidup.

Kemajuan ilmu pengetahuan dan teknologi lewat media informasi, TV, radio, internet, video dan alat komunikasi lainnya telah menyentuh daerah Gayo. Modernisasi ini ditandai dengan perubahan pola hidup yang hampir sama di belahan dunia ini, sehingga hidup generasi muda di Gayo sudah mengalami perubahan yang drastis ke arah sekuler dan liberal. Keadaan ini dapat mempengaruhi sikap dan karekter anak-anak di Gayo secara signifikan. Perubahan itu adalah spiritual mereka menipis, kurang dinamis dan kurang kreatif, degradasi moral dan silaturrahim berkurang. Hal ini akibat sistem tradisi pendidikan Gayo sudah hilang ditelan modernisasi.

Untuk mengatasi krisis pendidikan anak-anak Gayo ini perlu usaha reorientasi dengan pendekatan integrasi antara syariat Islam dengan tradisi adat pendidikan Gayo. Aplikasinya adalah memfungsikan dan kerja sama antara Dinas Syariat Islam, Lembaga Adat Gayo dan Majelis Permusyawaratan Ulama. Ketiga lembaga ini harus bersinergi untuk mengembalikan pendidikan anak Gayo pada ajaran Islam yang benar dan sesuai adat istiadat leluhur rakyat Gayo. Dengan cara itulah, generasi muda Gayo ini akan menjadi orang-orang yang shaleh, taqwa, berbudaya Islami tetapi maju dan modern yang kelak akan sejahtera baik di dunia maupun di akhirat.

\section{Daftar Pustaka}

Ali, Abdurrahim. 1986. Peran Islam Melahi Adat Gayo dalam Pembangunan Masyarakat Gayo. Takengon: Seminar Ilmu Pengetahuan Dan Kebudayaan

Abubakar, A.Y. 1976. Pandangan Islam Terhadap Hukum Waris Adat Gayo di Daerah Gayo Lut Kabupaten Daerah Tingkat II Aceh Tengah. Banda Aceh: IAIN Jamiah Ar-Raniry.

Abubakar, Al Yasa. 2004. Syariat Islam Di Provinsi NAD Paradigma, Kebijakan Dan Kegiatan. Banda Aceh: Dinas Syariat Islam NAD.

Hanafi, A. 1983. Filsafat Skolastik. Jakarta: Pustaka Alhusna. 
Ibrahim, Mahmud. 1986. Peranan Islam Melalui Adat Gayo Dalam Pembangunan Masyarakat Gayo. Dalam Seminar Ilmu Pengetahuan Dan Kebudayaan. Takengon: diselenggarakan MUI Aceh kerjasama PEMDA/MUI Aceh Tengah.

Madjid, Nurcholis. 1992. Islam Doktrin Dan Peradaban, Sebuah Telaah Kritis Tentang Masalah Keimanan, Kemanusiaan, dan Kemodernan. Jakarta: Yayasan Wakaf Paramadina.

Melalatoa, M.J. 1982. Kebudayaan Gayo. Jakarta: Balai Pustaka.

MPU NAD. 2008. Kumpulan Undang-Undang, Perda, Qanun dan Instuksi Gubernur Tentanag Keistimewaan NAD. Banda Aceh: MPU NAD.

Paeni, Mukhlis. 2003. Riak Di Laut Tawar Kelanjutan Tradisi Dalam Perubahan Di Gayo Aceh Tengah. Yogyakarta: Gajah Mada University Press.

Pinan, A.R. Aman. 1998. Hakikat Nilai-Nilai Budaya Gayo Aceh Tengah. Takengon: Pemerintah Daerah Aceh Tengah.

Rakhmat, Jalaluddin. 1991. Islam Aktual. Bandung: Mizan.

Raziq, Ali Abd. 1925. al-Islam wa Usul al-Hukm. Kairo: al-Matba'ah alMishriyah

Razi, Fakhruddin Muhammad. 1985. Tafsir Fakhr ar-Razi. Beirut: Dar alFikri.

Sou'yb, Joesoef. 1987. Riba Rente Bank Dan Masalah Aurat Wanita. Medan: Rimbow.

Syukri. 2006. Sarakopat Sistem Pemerintahan Tanah Gayo Dan Relevansinya Terhadap Peleksanaan Otonmi Daerah. Jakarta: Hijri Pustaka Utama

Syukri. 2012. Ulama Membangun Aceh. Medan: IAIN Press.

Weber, Eugene. 1972 The Western Tradition: From The Renaissance to The Present. Massachusetts: D.C. Heat and Company. 


\section{PEDOMAN UMUM}

1. Artikel yang ditulis untuk Jurnal el-Harakah adalah meliputi hasil pemikiran dan hasil penelitian di bidang Budaya Islam. Naskah diketik dengan huruf Times New Roman, ukuran 12 pts, dengan spasi 1,5 spasi, dicetak pada kertas A4 sepanjang maksimum 20 halaman, dan diserahkan dalam bentuk print-out sebanyak 3 eksemplar beserta filenya. Berkas (file) dibuat dengan Microsoft Word (ekstensi RTF).

2. Nama penulis dicantumkan tanpa gelar akademik dan ditempatkan di bawah judul artikel. Penulis dianjurkan mencantumkan nama lembaga, telepon, dan e-mail untuk memudahkan komunikasi.

3. Seluruh judul bagian dan sub-bagian dicetak tebal (bold), dan tidak menggunakan angka/nomor pada judul bagian.:

4. Sistematika penulisan artikel hasil pemikiran adalah: judul; nama penulis (tanpa gelar akademik); abstrak (maksimal 200 kata); kata kunci; pendahuluan (tanpa judul) yang berisi latar belakang dan tujuan atau ruang lingkup tulisan; bahasan utama (dapat dibagi ke dalam beberapa sub-bagian); penutup atau simpulan; daftar pustaka (hanya memuat sumber-sumber yang dirujuk).

5. Sistematika penulisan artikel hasil penelitian adalah: judul, nama penulis (tanpa gelar akademik), abstrak (maksimal 200 kata) yang berisi tujuan, metode, dan hasil penelitian, kata kunci, pendahuluan (tanpa judul) yang berisi latar belakang, sedikit tinjauan pustaka, dan tujuan penelitian, metode, hasil, pembahasan, simpulan dan saran, daftar pustaka (hanya memuat sumber-sumber yang dirujuk).

6. Sumber pustaka diutamakan adalah sumber-sumber primer berupa laporan penelitian Skripsi, Tesis, Disertasi, atau artikel-artikel penelitian dalam jurnal dan majalah ilmiah.

7. Perujukan dan pengutipan menggunakan teknik rujukan berkurung (nama, tahun: halaman). Pencantuman sumber pada kutipan langsung 
hendaknya disertai keterangan tentang nomor halaman tempat asal kutipan. Contoh: (Kaelan, 2005: 47).

8. Daftar Pustaka disusun diurutkan secara alfabetis dan kronologis.

\section{Buku}

\section{PENULISAN DAFTAR PUSTAKA}

Nama pengarang [atau editor]. Tahun terbit. Judul Buku. Tempat terbit: Nama penerbit.

\section{- Buku dengan Pengarang}

Abdullah, Amin. 2006. Islamic Studies di Perguruan Tinggi: Pendekatan Integratif dan Interkonektif. Yogyakarta: Pustaka Pelajar.

- Buku dengan Lembaga atau Organisasi sebagai Pengarang

[Depdikbud] Departemen Pendidikan dan Kebudayaan, Pusat Pembinaan dan Pengembangan Bahasa. 2010. Kamus Besar Bahasa Indonesia. Ed ke-3. Jakarta: Balai Pustaka.

[Fsaintek UIN Maliki] Fakultas Sains dan Teknologi, Universitas Islam Negeri Maulana Malik Ibrahim. 2009. Pedoman Penulisan Tugas Akhir. Malang: Fsaintek UIN Maliki.

\section{- Buku terjemahan:}

Wood, Alan dan Grant, Ted. 1995. Revolusi Berpikir dalam Ilmu Pengetahuan Modern. Terjemahan oleh Rafiq N. 2006. Yogyakarta: IRE Press.

\section{- Buku kumpulan artikel:}

Irawan, Irma dan Supriyanto, Andi [Eds]. 1999. Jurnalistik Kontemporer (Edisi ke-2, cetakan ke-1). Bandung: Salsabila Press.

\section{- Artikel dalam buku kumpulan artikel:}

Geertz, Clifford. 1999. Religion as a Cultural System. Dalam Garry E. Kessler, Philoshophy of Religion: Towards A Global Perspektif [hlm 11-12]. Belmont: Wadsworth Publishing Company.

\section{Surat Kabar}

Nama pengarang. Tanggal bulan tahun terbit. Judul. Nama surat kabar. Nomor halaman (nomor kolom). 
Kuncoro, Toha. 1 Desember, 2007. Pergulatan Menuju Perdamaian Palestina. Jawa Pos: 6 (kolom 2-5).

- Tulisan berita dalam koran (tanpa nama pengarang):

Surya. 31 Desember 2008. KPK Pelototi Dana Yayasan Instansi Negara. Halaman 3.

\section{Dokumen Resmi}

[Depdiknas] Departemen Pendidikan Nasional. 2002. Keputusan Menteri Pendidikan Nasional Republik Indonesia Nomer 045/U/2002 tentang Kurikulum Inti Pendidikan Tinggi. Jakarta: Depdiknas.

Makalah seminar, lokakarya, penataran, pelatihan, workshop:

Rahardjo, Mudjia. 2007. Metodologi Penulisan Artikel Jurnal Ilmiah. Makalah disajikan dalam Workshop Pelatihan Mutu Jurnal Ilmiah. Malang: Unit Informasi dan Publikasi (Infopub) Universitas Islam Negeri Malang. Tanggal 7-12 Desember.

\section{Acuan Melalui Internet}

\section{- Artikel dari Publikasi Eletronik}

Nama pengarang. Tahun penerbitan. Judul artikel. Nama jurnal. Volume (nomor) halaman. [tipe media]. Ketersediaan. [Tanggal, bulan dan tahun akses].

Sukandana, I Made. 2009. Kebo-keboan dan Ider Bumi Suku Using: Potret Inklusifisme Islam di Masyarakat Using Banyuwangi. Jurnal el Harakah. Volume 13, Nomor 2: Tahun 2011 Hal.169-el Harakah Vol.14 No.2 Tahun 2012.196. http://Infopub.uin-malang/el harakah.

\section{- Abstrak dalam Jurnal Ilmiah}

Nama pengarang, Tahun penerbitan. Judul artikel. Nama jurnal. Volume (nomor): abstrak [tipe media]. Ketersediaan. [Tanggal, bulan, dan tahun akses].

Supriyatna, Endang. 2008. Kepercayaan Tradisional dan Ketakwaan Terhadap Tuhan Yang Maha Esa dalam Sistem Sosial Budaya Masyarakat Betawi di DKI Jakarta, (Jurnal Penelitian, Vol. 40, no.1, 607-640. http:// Infopub.uin-malang/el harakah. 


\section{- Bahan Diskusi}

Nama pengarang, Tahun. penerbitan. Judul artikel. Nama forum diskusi. Ketersediaan. [Tanggal, bulan, dan tahun akses].

Afghani, Mohammad. 2010. Perkembangan Budaya Islam di Indonesia. Indonesia in Islamic Culture. Indonesianculture@yahoo.co.uk, [8 Juni 2010].

\section{- Pengiriman e-mail Pribadi}

Hayati, Elok Kamilah [eloksunardji@yahoo.com] 5 Mei 2010. Artikel untuk Jurnal el Harakah. E-mail kepada Jurnal el Harakah [elharakahjurnal@ gmail.com].

el Harakah Vol.17 No.2 Tahun 2015 